Review

\title{
Types of Hair Dye and Their Mechanisms of Action
}

\section{Simone Aparecida da França, Michelli Ferrera Dario *, Victoria Brigatto Esteves, André Rolim Baby and Maria Valéria Robles Velasco}

School of Pharmaceutical Sciences, University of São Paulo, 05508-000 São Paulo, Brazil; E-Mails: simone1002af@uol.com.br (S.A.F.); victoria.brigatto@gmail.com (V.B.E.); andrerb@usp.br (A.R.B.); mvrobles@usp.br (M.V.R.V.)

* Author to whom correspondence should be addressed; E-Mail: michelli.dario@usp.br; Tel.: +55-11-3091-3623; Fax: +55-11-3815-4418.

Academic Editor: Enzo Berardesca

Received: 18 February 2015 / Accepted: 2 April 2015 / Published: 22 April 2015

\begin{abstract}
Hair color change by dye application is a common procedure among women. Hair dyes are classified, according to color resistance, into temporary, semipermanent, demipermanent and permanent. The first two are based on molecules which are already colored. Temporary dyes act through dye deposition on cuticles, but semipermanent may penetrate a little into the cortex and so the color resists up to six washes. Demipermanent and permanent dyes are based on color precursors, called oxidation dyes, and the final shade is developed by their interactions with an oxidizing agent, but they differ from the alkalizing agent used. In oxidation systems, there is an intense diffusion of the molecules into the cortex, what promotes a longer color resistance. Dyes and color precursors present differences related to chromophore groups, hair fiber affinity, water solubility, and photo stability. The aim of this review is to discuss the differences among hair dye products available in the market and their action mechanisms, molecular structures, application methods, and some aspects of formulations.
\end{abstract}

Keywords: hair; dye; temporary; semipermanent; permanent; action mechanism 


\section{Introduction}

The use of cosmetics in order to change hair color, such as hair dye products, occurs with high frequency, mostly among the female population [1]. However, these hair dyes, due to their action mechanisms, may cause serious damage to the hair fiber structure [2].

Throughout human history, many people have wished to change the appearance of their hair because it was a way to differentiate the social status. Hair dye has been used since Ancient Egyptian times when Rameses II reinforced red hair color using henna. In Ancient Greece, the hair was bleached with a rinse of potassium solution and rubbed with a type of ointment made of yellow flower petals and pollen [3]. Nowadays, hair dyes are in an important phase of development and since the Second World War, great progress in discoveries and applications of new synthetic dyes has occurred.

Brazil is a country that, because of its high miscegenation, presents almost all the hair types. Furthermore, because of the great importance that women give to their hair treatments, Brazil is now the world leader in hair dye products [4]. Nevertheless, the dye market has focused on exports, mainly to South American countries.

\section{Composition and Morphology of Hair Fiber}

Hair is an annex of the epidermis and covers the external tissues of most mammal. It is also considered an adornment. It works as a thermal regulator and protects the head and the skin from the sun due to the presence of melanin [5]. Humans have between 90 and 150 thousands of hair fibers on the scalp that grow $1 \mathrm{~cm} /$ month $(0.37 \mathrm{~mm} /$ day $)$, and the normal amount of hair lost is between 50 and 100 fibers per day. The hair diameter varies from 15 to $110 \mu \mathrm{m}$, depending on the race [6]. Caucasian hair is usually thin and fine, may have waves, and is circular under the cross-section view (ellipticity of 1.25). The African hair type (wavy to curly) has a larger diameter, with a slightly oval cross-section (ellipticity of 1.75). Lastly, Mongolian hair also has a larger diameter but varies from flat to wavy with a cross-section similar to Caucasian hair (ellipticity of 1.35 ) $[7,8]$.

Hair or fur is composed of dead skin cells which pass through a keratinization process, derived from hair or hair follicles that are invaginations that protrude into the dermis or hypodermis [9]. Keratin, the main protein found in the hair fiber, is produced by the keratinocytes of the epithelial tissue invagination. Small amounts of water-soluble substances are also present, such as pentene, phenols, uric acid, glycogen, glutamic acid, valine and leucine [10].

The hair shaft is divided into four main distinct structures: cuticle, cortex, cell membrane complex (CMC), and the medulla [11].

The cuticles (which consists of amorphous and protein material) are the most external part of the hair strand and ensure chemical resistance. These cuticles carry out the function of regulating the amount of water in the hair structure, which keeps its physical properties. It contains six to ten layers of overlapping cells in the longitudinal direction of the fiber [12]. The damage to the cuticle can be caused by weather or mechanical friction such as combing and brushing. The excessive use of shampoo and other inappropriate cosmetics may damage hair [13]. Each cuticle cell contains an external thin membrane $(5.0$ to $10.0 \mathrm{~nm}$ ) probably formed by a layer of fatty acid connected to the 
protein layer through thioester bonds, which generates cysteine residues responsible for the apparent hydrophobic character of the fiber [12].

The cuticle contains three important layers: the A-layer $(120 \mathrm{~nm})$ with a high content of cysteine and highly cross-linked; the exocuticle (B-layer), also rich in cysteine and occupying about the half of the cell volume; and, finally, the endocuticle, a layer with a low content of cysteine and relatively high levels of basic (lysine, arginine) and diacids (aspartic and glutamic acids) amino acids [7,14].

The cortex is the principal component of the hair, consisting of cylindrical cells of about 1 to $6 \mu \mathrm{m}$ of thickness and $100 \mu \mathrm{m}$ of length. It forms the matrix where other proteins and keratin are located, and composes the larger part of the fibrous mass of human hair, being formed by intracellular and intercellular material [15]. The cortex represents $90 \%$ of its total weight and consists of cells filled with keratin, with an organization that provides mechanical properties to the fibers [16]. The cortical cells, adjacent to the cuticle, are flatter and contain less sulfur than the cells inside the cortex, which are rich in cystine (two cysteine), amino acids, lysine and histidine, in addition to the melanin granules [7].

The matrix comprises the major structure of the hair and contains a high concentration of disulfide bonds. It presents considerable swelling when in contact with water and forms a lightly cross-linked gel structure. Although there are amorphous regions, the matrix presents small parts with structural organization [17]. It exhibits keratin macrofibrils aligned in the direction of the hair strand and melanin granules which are responsible for the hair color and its photo protection.

The $\mathrm{CMC}$ is an important layer in the hair structure consisting of cell membranes and adhesive material that "glue" or link the cortical and the cuticle cells. Chemically, CMC is composed of proteins, polysaccharides, and ceramides. It is also responsible for the hair's natural moisture, making it bright, transparent, and hydrated [6]. Its outer lipid layer forms the epicuticle and the inner lipid layer is located between the cuticle cells which consist of the $\delta$-layer, formed by proteins with a low content of cystine $(<2 \%)$ and richer in polar amino acids $(12 \%$ basic and $17 \%$ acid). The CMC and the endocuticle are usually referred to as non-keratinized regions because they have a low level of sulfur amino acids and studies have proven that they are important pathways to the diffusion of molecules to inner regions of the hair fiber [7].

The medulla is the innermost region and its presence along the hair is usually discontinuous or even absent and does not interfere with the hair structure [11]. The medulla can be empty or filled with sponge keratin, can serve as a pigment reservoir, and can contribute to the brightness of the hair. The lipid concentration inside the medulla is bigger than anywhere else in the hair [18].

\section{Hair Dyes}

Hair dying systems can be divided into two main categories, oxidative or non-oxidative, and also according to the color durability after the application on hair strands: temporary, semipermanent, demipermanent and permanent $[10,19]$.

Many studies established the diffusion path of the dye molecule to the inner hair fiber. It involves the permeation of the molecules into intercuticular regions, passing through non-keratinized regions of the endocuticle and the intracellular cement. In later stages, it migrates to keratinized regions and, eventually, reaches the macrofibrils, before being incorporated into the matrix [7]. 
The temporary and semipermanent non-oxidative dyes are based on colorful molecules, named dye deposition, because the dye molecule only interacts with the hair cuticles. When there is a small penetration of the molecules into the hair cortex, they are named semipermanent products and can be resistant up to six washes. The demipermanent and permanent oxidative are based on precursors, named oxidation dyes, whose color characteristics are developed by means of the interaction with an oxidizing agent, and present longer lasting color [20].

\subsection{Temporary Non-Oxidative Hair Dyeing}

The temporary non-oxidative dyeing has a reduced permanence time on the fiber, leaving the hair after the first shampoo washing because dye presents high molecular weight and deposits on the hair surface without the capacity of penetrating the cortex [15]. This type of dye does not have the power of whitening the hair strand and, therefore, it is indicated only to add new nuance and not to change its color [1]. In white, blond or bleached hairs, it is possible to add a new color with a more noticeable effect because the hair strand's background color allows the visualization of the new applied color.

The temporary dye can be used for specific purposes such as adding colorful reflections, removing the yellowish effects of the white hair, and covering a small quantity of white hair [21]. It allows the dyeing of hair containing up to $15 \%$ white hair, due to their ability to deposit on the hair strands.

These dyes, that present acid characteristics [22] usually have high molar mass, according to the structures presented in Table 1. They contain anionic characteristics and are selected to allow the maximum solubility in water and the minimum penetration in hair so it is removed in the first washing [17]. They are presented as shampoo, gel, emulsion and solution (liquid) with two different forms of application: continuous application (progressive) or single application, with one wash at the end of the application process to remove the unabsorbed dye excess on the hair strand.

Table 1. Structural and molecular formulas of acid dyes used in temporary non-oxidative dye formulation [23]. Legend: INCI, International Nomenclature of Cosmetic Ingredients; CAS, Chemical Abstract Service.

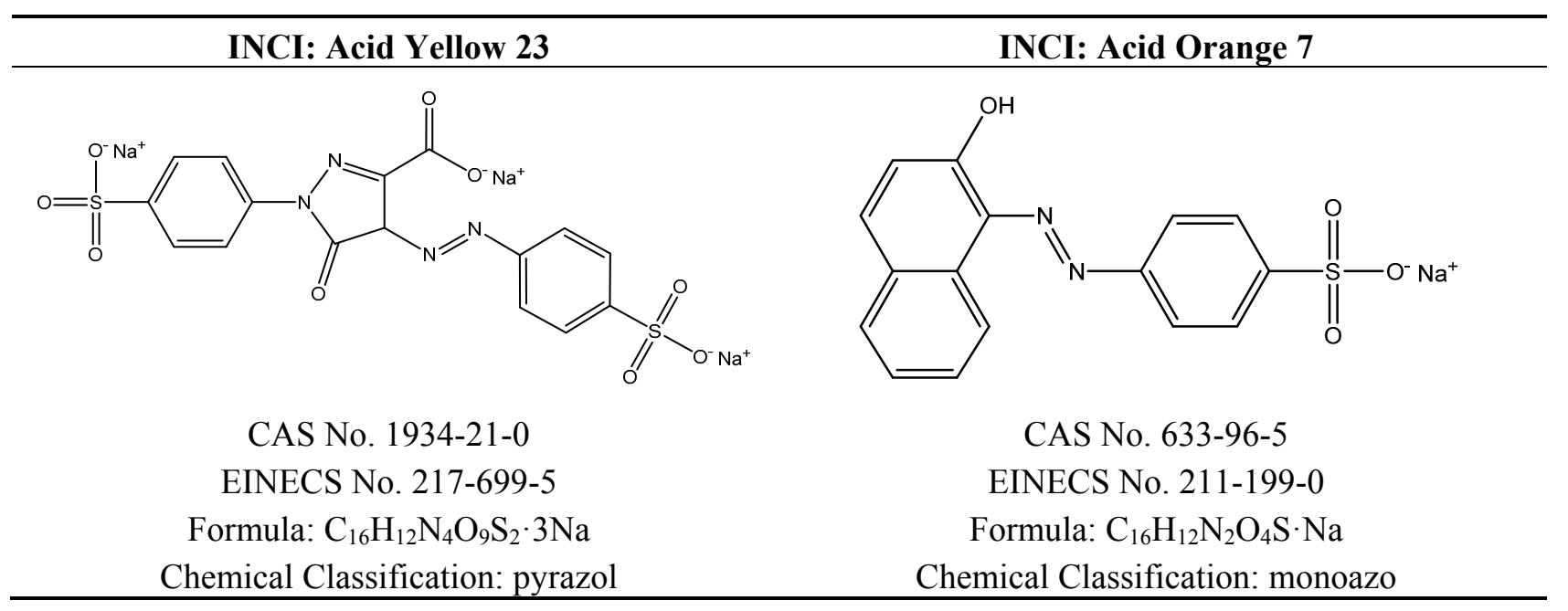


Table 1. Cont.

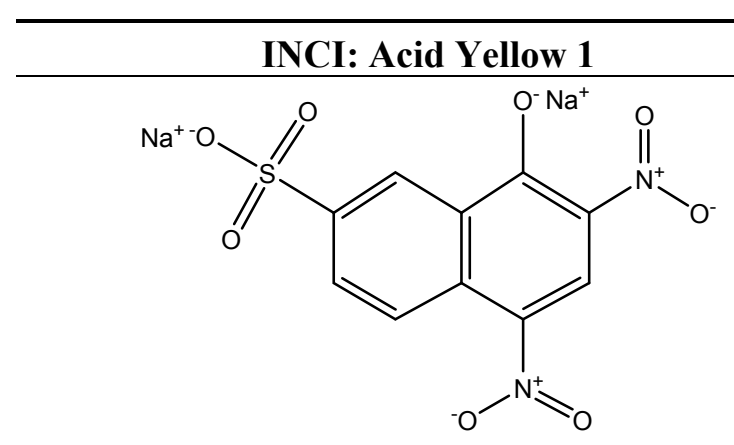

CAS No. 846-70-8

EINECS No. 212-690-2

Formula: $\mathrm{C}_{10} \mathrm{H}_{6} \mathrm{~N}_{2} \mathrm{O}_{8} \mathrm{~S} \cdot 2 \mathrm{Na}$

Chemical Classification: nitro
INCI: Acid Red 33<smiles>Nc1cc(S(=O)(=O)O[Na])cc2cc(S(=O)(=O)O[Na])c(N=Nc3ccccc3)c(O)c12</smiles>

CAS No. 3567-66-6

EINECS No. 222-656-9

Formula: $\mathrm{C}_{16} \mathrm{H}_{13} \mathrm{~N}_{3} \mathrm{O}_{7} \mathrm{~S}_{2} \cdot 2 \mathrm{Na}$

Chemical Classification: monoazo

\section{INCI: Acid Red 92}<smiles>[NH3+]Oc1c(Br)cc2c(-c3c(Cl)c(Cl)c(Cl)c(Cl)c3C(=O)[OH2+])c3cc(Br)c(=O)c(Br)c-3oc2c1Br</smiles>

CAS No. 18472-87-2/4618-23-9

EINECS No. 242-355-6

Formula: $\mathrm{C}_{20} \mathrm{H}_{4} \mathrm{Br}_{4} \mathrm{Cl}_{4} \mathrm{O}_{5} \cdot 2 \mathrm{Na}$

Chemical Classification: xanthene

INCI: Acid Violet 43<smiles></smiles>

CAS No. 4430-18-6

Formula: $\mathrm{C}_{21} \mathrm{H}_{15} \mathrm{NO}_{6} \mathrm{~S} \cdot \mathrm{Na}$

Chemical Classification: anthraquinone

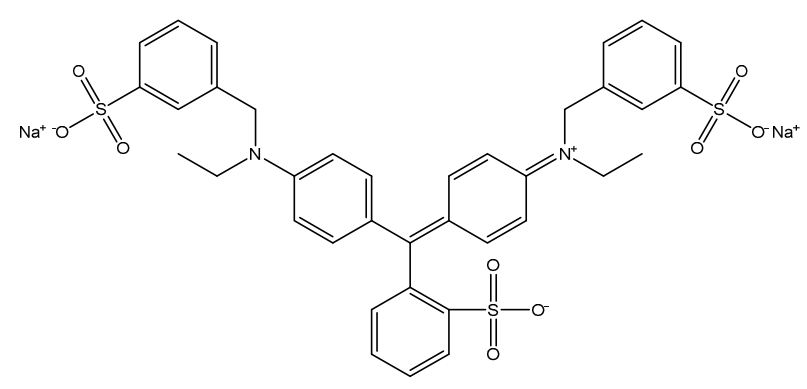

CAS No. 3844-45-9

EINECS No. 223-339-8

Formula: $\mathrm{C}_{37} \mathrm{H}_{36} \mathrm{~N}_{2} \mathrm{O}_{9} \mathrm{~S}_{3} \cdot 2 \mathrm{Na}$

Chemical Classification: triphenylmethane<smiles></smiles>

CAS No. 1064-48-8

EINECS No. 213-903-1

Formula: $\mathrm{C}_{22} \mathrm{H}_{14} \mathrm{~N}_{6} \mathrm{O}_{9} \mathrm{~S}_{2} \cdot 2 \mathrm{Na}$

Chemical Classification: diazo 
Frequently, two to five substances are necessary to reach the desired hair color because just one substance does not achieve natural shades. Some formulations use two molecules to remove the yellowish effect in white hair and also four to five substances are mixed to reach the red, brown, and black shades [17].

The temporary non-oxidative formulations as single applications, present higher dye concentrations, ranging from $0.1 \%$ to $2.0 \%(w / w)$ and have the purpose of promoting a stronger dyeing effect. However, the limit of deposition must be always respected because this type of application will not cover gray hair satisfactorily in people with more than $30 \%$ of white hair fibers. The formulation must get in contact with hair for about $30 \mathrm{~min}$ and results will occur immediately. It is suitable for those who wish for fantasy colors [24]. It resists from three to six washes when applied to bleached hair, like semipermanent dyeing.

\subsection{Semi-Permanent Non-Oxidative Hair Dyeing}

These formulations contain basic or cationic dyes with low molar mass, which has a high affinity for hair keratin and resists from three to six washes [10]. The hair dyeing process does not involve oxidation reaction; the application is simple and lasts from 10 to $40 \mathrm{~min}$, followed by rinsing $[1,25]$. Several products are available in the market: lotions, shampoos, mousses and emulsions. These cosmetic forms must have the ideal viscosity so that they do not flow during the application [20]. Dyes with low molar mass penetrate slightly in the cortex, especially because of the high $\mathrm{pH}$ value of the product that promotes the cuticles opening [15].

Demipermanent hair products promote major hair color durability (resistance up to 20 washes) because they consist of a mix of semipermanent molecules with oxidation dye precursors, applied with hydrogen peroxide $\left(\mathrm{H}_{2} \mathrm{O}_{2}\right)$ [20].

Another option of formulation involves mixing nitro aniline dyes with basic or acid dyes which aim for a better color result and a bigger resistance to washes, considering the high affinity of the two families of dyes. The hair space not filled with the basic dyes will be occupied by nitro anilines, thus promoting a much more uniform color in the first application. Table 2 contains the molecules allowed and used in cosmetic formulations for semipermanent hair dyeing.

The nitro anilines are molecules comprised of a neutral aromatic amine or anthraquinone derivatives and all are classified as highly polar and present mono, di, or tri nuclear rings. These dyes are diffused through the hair fiber and are retained by weak Van de Waals bonds [17]. Under similar conditions, the larger molecules with tri aromatic rings are removed more slowly from hair than the smaller, mononuclear ones [26].

The cationic dyes shown in Table 3 are used in both temporary and semipermanent dyeing. They permit reflective effects and are excellent for instantaneous color effects. The similarities between the size of the cationic molecules grant substantivity to the hair in a homogenous way, ensuring the color reproducibility and the resistance to washing uniformly. In other words, all dyes are removed simultaneously during this process [24]. 
Table 2. Structural and molecular formulas of nitro anilines used in semipermanent hair dyeing formulation [23]. Legend: INCI, International Nomenclature of Cosmetic Ingredients; CAS, Chemical Abstract Service; HC, Hair Color.

INCI: HC Yellow No. 2<smiles>O=[N+]([O-])c1ccccc1NCCO</smiles>

CAS No. 4926-55-0

EINECS No. 225-555-8

Empirical Formula: $\mathrm{C}_{8} \mathrm{H}_{10} \mathrm{~N}_{2} \mathrm{O}_{3}$

Chemical Classification: nitro aniline

INCI: 4-hydroxypropylamino-3-nitrophenol
INCI: HC Red No. 3<smiles>Nc1ccc(NCCO)c([N+](=O)[O-])c1</smiles>

CAS No. 2871-01-4

EINECS No. 220-701-7

Empirical Formula: $\mathrm{C}_{8} \mathrm{H}_{11} \mathrm{~N}_{3} \mathrm{O}_{3}$ Chemical Classification: nitro aniline<smiles>O=[N+]([O-])c1cc(O)ccc1NCCCO</smiles>

CAS No. 92952-81-3

EINECS No. 406-305-9

Empirical Formula: $\mathrm{C}_{9} \mathrm{H}_{12} \mathrm{~N}_{2} \mathrm{O}_{4}$
INCI: $N, N^{\prime}$-bis-(2-hydroxyethyl)-2-nitrophenylenediamine

Chemical Classification: nitro aniline<smiles>O=[N+]([O-])c1cc(NCCO)ccc1NCCO</smiles>

CAS No. 84041-77-0

EINECS No. 281-856-4

Empirical Formula: $\mathrm{C}_{10} \mathrm{H}_{15} \mathrm{~N}_{3} \mathrm{O}_{4}$ Chemical Classification: nitro aniline

\section{INCI: HC Blue No. 2}<smiles>O=[N+]([O-])c1cc(N(CCO)CCO)ccc1NCCO</smiles>

CAS No. 33229-34-4

EINECS No. 251-410-3

Empirical Formula: $\mathrm{C}_{12} \mathrm{H}_{19} \mathrm{~N}_{3} \mathrm{O}_{5}$ 
The good performance of semipermanent dyes is directly related to their great water solubility. In general, the nitro anilines are not soluble in water and require a glycol or glycol derivative, such as glycerin, to be solubilized in the formulation. Specific solvents, such as mixtures of quaternary salts of high molecular weight, such as Quaternium-80, benzyl alcohol, and glycols are used to ensure not only their solubility in the formulation but also during application and product storage [24,27].

Cationic dyes exhibit excellent affinity for damaged hair, because positive sites of the dye molecule bind to negative sites on the hair fiber by an ionic bond [28]. They allow greater resistance to washing when compared to nitro anilines.

Table 3. Structural and molecular formulas of cationic dyes used in semi-permanent hair dyeing formulation [23]. Legend: INCI, International Nomenclature of Cosmetic Ingredients; CAS, Chemical Abstract Service.<smiles>CN(C)c1ccc(/N=N/c2n(C)cc[n+]2C)cc1</smiles>

CAS No. 77061-58-6

EINECS No. 278-601-4

Empirical Formula: $\mathrm{C}_{13} \mathrm{H}_{18} \mathrm{~N}_{5} \cdot \mathrm{Cl}$ Chemical Classification: direct dye

INCI: Basic Brown 16<smiles>C[N+](C)(C)c1ccc2ccc(O)c(/N=N/c3ccc(N)cc3)c2c1</smiles>

CAS No. 26381-41-9

EINECS No. 247-640-9

Empirical Formula: $\mathrm{C}_{19} \mathrm{H}_{21} \mathrm{~N}_{4} \mathrm{O} \cdot \mathrm{Cl}$ Chemical Classification: direct dye<smiles>COc1ccccc1/N=N/c1c(O)ccc2ccc([N+](C)(C)C)cc12</smiles>

CAS No. 68391-30-0

EINECS No. 269-941-4

Empirical Formula: $\mathrm{C}_{20} \mathrm{H}_{22} \mathrm{~N}_{3} \mathrm{O}_{2} \cdot \mathrm{Cl}$ Chemical Classification: direct dye

INCI: Basic Brown 17<smiles>C[N+](C)(C)c1ccc2c(c1)C(=NNc1ccc(N)c([N+](=O)[O-])c1)C(=O)C=C2</smiles>

CAS No. 68391-32-2

EINECS No. 269-940-0

Empirical Formula: $\mathrm{C}_{19} \mathrm{H}_{20} \mathrm{~N}_{5} \mathrm{O}_{3} \cdot \mathrm{Cl}$

Chemical Classification: direct dye 
Table 3. Cont.

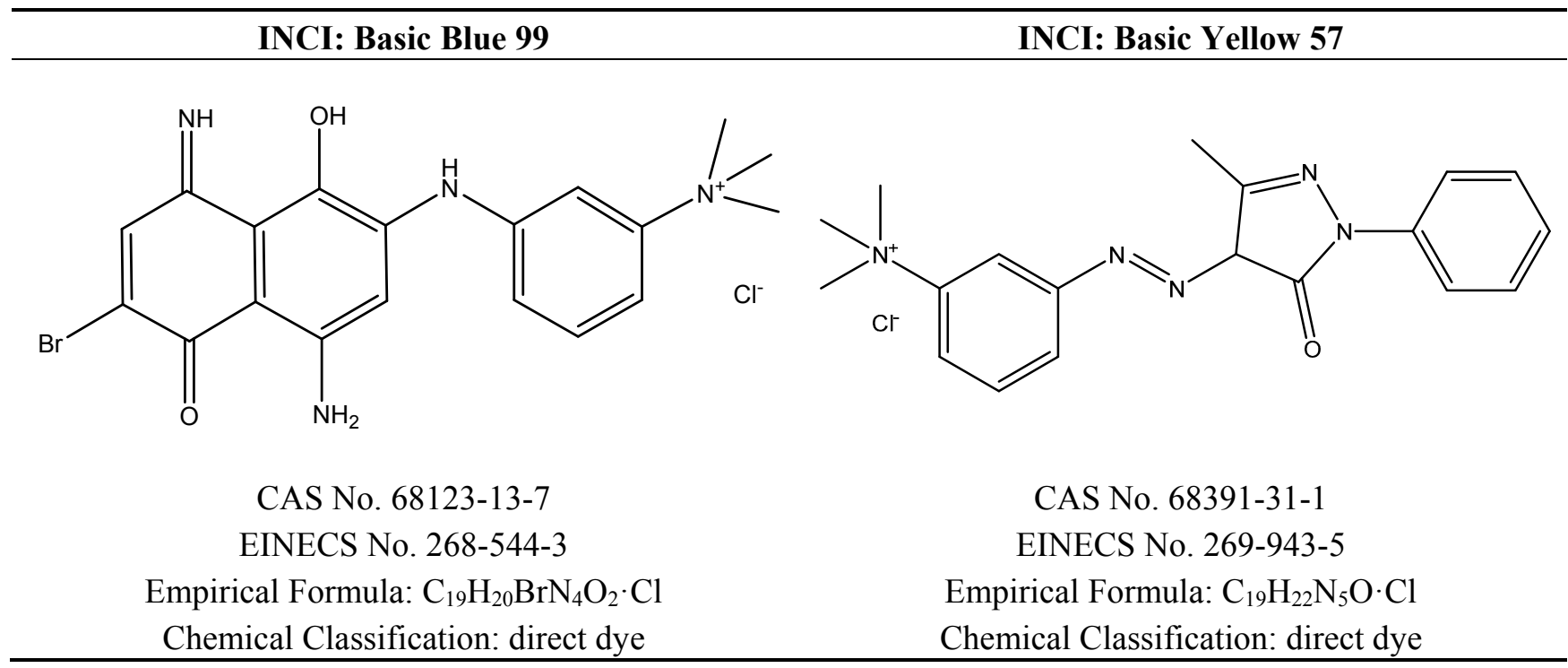

The cationic dyes are water-soluble; however, they also require the addition of solvents to ensure the homogeneity of the color and prevent recrystallization during storage because, in recrystallized form, the molecule does not provide the cationic sites to bind to hair strands [24].

The $\mathrm{pH}$ control is essential for color stability. A weak base such as mono ethanolamine must be added to achieve a $\mathrm{pH}$ of 9.0 , and then a weak acid such as $10 \%$ citric solution is used to lower the $\mathrm{pH}$ value to 6.0. This way, a buffer system which ensures the $\mathrm{pH}$ maintenance of the finished product during shelf life is formed [24].

Other dyes, such as metallic and vegetables derivatives, are also considered to be semipermanent dyes and can be used in hair dyeing. Henna is the most widely used vegetable dye for hair, promoting reddish orange color shades $[1,25]$. In some commercial products, it is mixed with other dyes to increase the range of color. It consists of the dried leaves of the Lawsonia alba plant, growing in North Africa, in the Midwest, and in India [19,20]. Its coloring properties are due to the presence of the substance 2-hydroxy-1,4-naphthoquinone, soluble in hot water and substantive to hair keratin in pH $5.5[10,29]$.

Another vegetable dye commonly used to obtain yellow shades is chamomile [1] that promotes greater light reflection. Of all the species of chamomile, only Anthemis nobilis (Roman Chamomile) and Matricaria chamomillae (German chamomile) have cosmetic applications, and both are substantive to hair. The active ingredient of the flowers is 1,3,4-trihydroxyflavone, also known as apigenin [10].

The metallic dyes are derived from silver salts, lead, and bismuth and are traditionally used by men because the dyeing effect is not immediate and does not promote $100 \%$ of the white hair coverage. The darkening of the hair strands occurs gradually, promoting a more natural appearance, which satisfies the general public. The use is limited to the number of gray hair strands [1]. Therefore, hair with a lot of white fibers cannot have a satisfactory result because of the leak of homogeneity in the final color.

Products containing diluted lead acetate are applied to the hair daily and do not require washing, so the metal salt is exposed to air oxygen and also reacts with sulfur from keratin. These reactions 
generate a mixture of metallic oxides and insoluble sulfides [10], responsible for gradual darkening of gray hair [20].

A disadvantage of the metallic dyeing process is the lack of control in the color progression because of the composition of hair, which is based on keratin. The keratin reduction will result in different colors, so after the first applications, hair can present greenish or yellowish shades. However, the final result is natural because the color develops progressively to more usual shades, such as brown and black, and coverage of $100 \%$ of white hair strands is impossible.

\subsection{Permanent Oxidative Hair Dyeing}

The permanent hair dyes are commonly used [1] because this category provides greater efficacy of permanent dyeing, resistance to shampoo washes and other external factors, such as drying, friction, light, and others. This category represents about $80 \%$ of the sold hair dyes [10] and gets any shade, covering up to $100 \%$ of white hair strands. Also, it is possible to have dark and light natural hair color [21] due to the combination of the oxidizing agents with the ammonia hydroxide. The principal difference between the demipermanent hair dye in comparison with a permanent one is the alkalizing agent used because, in the first, monoethanolamine with low color lightening power is used [28].

Color formation happens upon mixture and involves complex reactions between precursors in the presence of an oxidizing agent [20]. The precursors can be classified into two categories: oxidation basis or primary intermediaries, and the couplers or reaction modifiers [10].

The reaction occurs in an alkaline medium that promotes the opening of the cuticles that allows the penetration of the dyes' molecules into the cortex. The oxidizing agent permits the beginning of the reaction that occurs in the cortex and results in a colorful complex with high molar mass, which avoids the exit of molecules formed in the hair. Part of the reaction also happens on the cuticles and the molecules are removed in the first washes [30,31].

The ammonia hydroxide and ethanolamines are the most alkalizing agents used. A mixture of surfactants and solvents is used to disperse the dye molecules and ensure the hair wetting. A small amount of reducing agent is added to prevent auto-oxidation of the dyes during storage of the finished product [20], which may be formulated as an emulsion, gel, solution and powder.

The reactions involved in the formation of permanent dyes are redox types and require four major components: the aromatic amine with substitutions at positions ortho or para (hydroxy or amino) as the coupling bases; the reaction modifiers; an alkalizing compound; and an oxidizing agent.

\subsubsection{Coupling Bases}

Bases are aromatic compounds derived from benzene, substituted by at least two electron donor groups such as $\mathrm{NH}_{2}$ and $\mathrm{OH}$ in para or ortho positions to confer the property of easy oxidation [10], acting as a color developer [28]. Two major compounds are used such as $p$-phenylenediamine (Scheme 1) and $p$-aminophenol (Scheme 2). 


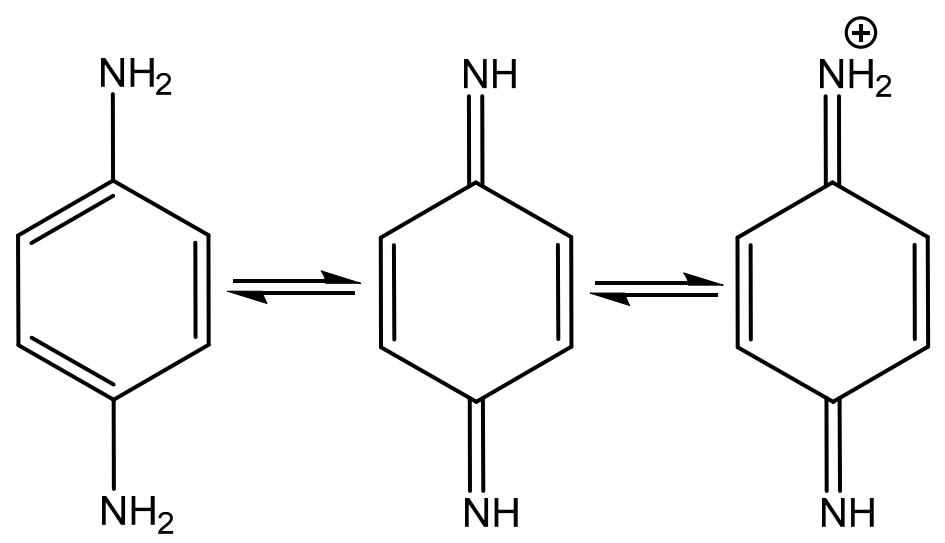

Scheme 1. Structural formula of $p$-phenylenediamine (PPD). INCI name: phenylenodiamine. CAS No. 106-50-3. EINECS No. 203-404-7. Formula: $\mathrm{C}_{6} \mathrm{H}_{8} \mathrm{~N}_{2}$. Chemical classification: aromatic amine [23]. Legend: INCI, International Nomenclature of Cosmetic Ingredients; CAS, Chemical Abstract Service.

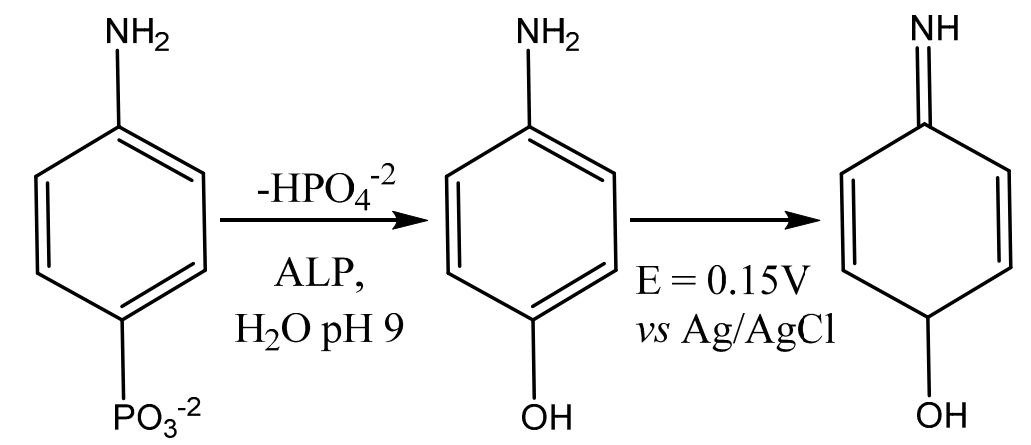
p-aminophenyl -aminophenol quinonimide phosphate

Scheme 2. Structural formula of $p$-aminophenol (PAP). INCI name: $p$-aminophenol. CAS No. 123-30-8. EINECS No. 204-616-2. Formula: $\mathrm{C}_{6} \mathrm{H}_{7} \mathrm{NO}$. Chemical classification: substitute phenol [23].

\subsubsection{Reaction Modifiers}

Reaction modifiers, also called couplers, are aromatic compounds derived from benzene and substituted by groups such as $\mathrm{NH}_{2}$ and $\mathrm{OH}$ in the meta position, which does not present easy oxidation by $\mathrm{H}_{2} \mathrm{O}_{2}$ [10]. They do not produce significant color alone but can modify them when used as primary intermediaries and oxidants [28]. There are many reaction modifiers available in the market, and some of the most important are shown in Table 4. 
Table 4. Molecular and structural formulas of reaction modifiers [23]. Legend: INCI, International Nomenclature of Cosmetic Ingredients; CAS, Chemical Abstract Service.

INCI: 4-chlororesorcinol<smiles>Oc1ccc(Cl)c(O)c1</smiles>

CAS No. 95-88-5

EINECS No. 202-462-0

Empirical Formula: $\mathrm{C}_{6} \mathrm{H}_{5} \mathrm{ClO}_{2}$
INCI: 2,4-diaminophenoxyethanol HCI<smiles>Nc1ccc(OCCO)c(N)c1</smiles>

CAS No. 66422-95-5

EINECS No. 266-357-1

Empirical Formula: $\mathrm{C}_{8} \mathrm{H}_{12} \mathrm{~N}_{2} \mathrm{O}_{2} \cdot 2 \mathrm{HCl}$

Chemical Classification: halogenated phenol Chemical Classification: aromatic amine salt<smiles>COc1ccc(NCCO)cc1N</smiles><smiles>O=S(=O)(O)O</smiles>

CAS No. $83763-48-8$

CAS No. 2835-95-2

EINECS No. 280-734-8

Empirical Formula: $\mathrm{C}_{9} \mathrm{H}_{14} \mathrm{~N}_{2} \mathrm{O}_{2} \cdot \mathrm{H}_{2} \mathrm{O}_{4} \mathrm{~S}$

EINECS No. 220-618-6

Empirical Formula: $\mathrm{C}_{7} \mathrm{H}_{9} \mathrm{NO}$

Chemical Classification: aromatic amine salt

INCI: $m$-aminophenol Chemical Classification: aromatic substitute<smiles>Nc1cccc(O)c1</smiles>

CAS No. 591-27-5

EINECS No. 209-711-2

Empirical Formula: $\mathrm{C}_{6} \mathrm{H}_{7} \mathrm{NO}$

Chemical Classification: substitute phenol
INCI: Resorcinol<smiles>Oc1cccc(O)c1</smiles>

CAS No. 108-46-3

EINECS No. 203-585-2

Empirical Formula: $\mathrm{C}_{6} \mathrm{H}_{6} \mathrm{O}_{2}$ Chemical Classification: phenol

\subsubsection{Alkalizing Compounds}

The addition of alkalizing compounds is necessary for the process of hair dyeing to promote the proper $\mathrm{pH}$ value for the beginning of the oxidation reaction. The most commonly alkalizing compounds used are ammonia, in the form of ammonium hydroxide, and monoethanolamine, when the formulation contains water, or sodium silicate when it is in solid form (powder). 
When ammonia is used, it is possible to cover $100 \%$ of white hair and to remove the natural pigments present in hair as the melanin. This type of dye is considered permanent because, after the formation of the colored polymer in the inner of the cortex, its complete removal is not possible. However, some polymers formed from the reaction between couplers and precursors can be eliminated by reducing agents such as sodium hydrosulfite [10].

The addition of monoethanolamine (MEA) is required to maintain optimum alkaline $\mathrm{pH}$ for the reaction. However, this substance does not oxidize the melanin. Thus, products containing MEA instead of ammonia hydroxide are suitable for maintenance of similar shades or to dark hair [24].

\subsubsection{Reducing Agents}

Reducing agents are added to oxidative dye formulations to retard the reaction between bases and reaction modifiers and to prevent the initiation of the reaction in the packaging tube during the storage time. One of the molecules most used for such applications is sodium metabisulfite (MBS).

\subsubsection{Antioxidants}

Antioxidants are necessary to avoid the reaction beginning before the addition of the oxidant itself. It is recommended to use a water-soluble antioxidant because the manipulation of bases and reaction modifiers could initiate the oxidative reaction, which may interfere with the final color of the product. One of the molecules most frequently used for this purpose is the erythorbic acid (AEB). It is also recommended to use an oil-soluble antioxidant when emulsion is used as a vehicle for hair dyes because this avoids the yellowing of wax and the oxidation of bases and reaction modifiers. One of the most used molecules is T-butylquinone (TBQ) [24].

\subsubsection{Oxidants}

There are basically two types of oxidants used: hydrogen peroxide, when the vehicle is water, and sodium persulfate, when it is a powder. The peroxides are very unstable, requiring the use of stabilizers such as sodium stannate and the pentasodium pentetate [24]. They are usually used in the form of emulsion, so-called "creamy hydrogen peroxide".

\subsubsection{Vehicles}

The oxidative dye in the form of emulsion is the highest selling product in the market, but other carriers are available such as gels, solutions (liquid), and powders. The preparation of the emulsion begins with adding the dye mixture to the reducing agents, antioxidants, and ammonium hydroxide in $20 \%$ of the aqueous phase. The other $80 \%$ of water is added in a manufacturing tank and heated to $70{ }^{\circ} \mathrm{C}$ under constant agitation. After reaching the temperature, all the wax and the emulsifying agents are added, maintaining a constant stirring until cooling to $40{ }^{\circ} \mathrm{C}$, when the remaining $20 \%$ of the water previously prepared is added. It is recommended to measure the ammonia content at the end of the process and to ensure that the amount of alkalizing is sufficient to complete the reaction after $24 \mathrm{~h}$. Because it is very volatile, a small amount of ammonia can be lost during the process, so an adjustment is necessary before packaging [24]. 


\subsubsection{Hair Color Formation}

Bandrowski's base (Figure 1) may be formed during the color formation process by the reaction of $p$-phenylenediamine (PPD) coupling base in alkaline medium containing hydrogen peroxide [32]. It is a compound that reacts preferentially with the modifiers presented in Table 4 for the formation of colored compounds which rise gradually. This reaction occurs in stages until the final formation of the color, so the amounts of coupling bases and modifiers vary with the desired final color [33]. About 3\% to 5\% of PPD becomes a Bandrowski's base, which is present in most oxidation reactions but does not affect the final hair color [34].

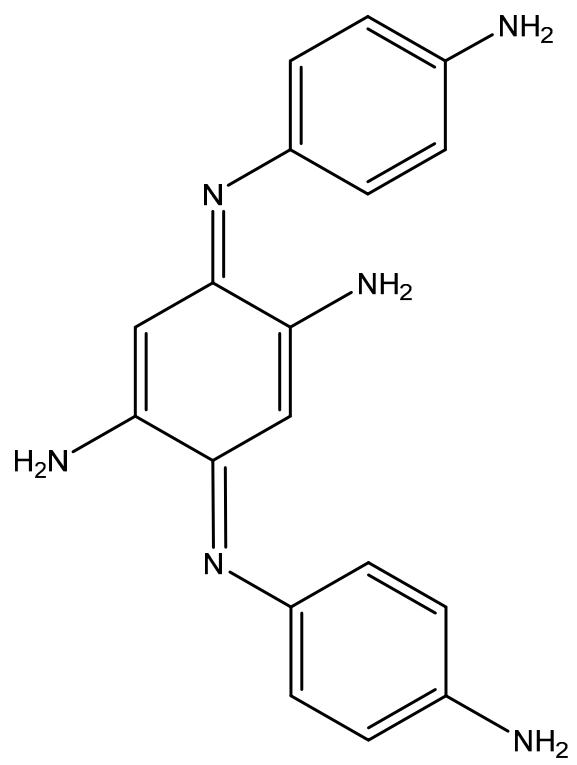

Figure 1. Bandrowski's base. CAS No. 20048-27-5. Formula: $\mathrm{C}_{18} \mathrm{H}_{18} \mathrm{~N}_{6}$ [33].

The intermediate compounds have similar sizes and, therefore, an easy and uniform penetration occurs inside the hair [34]. The critical diameter size of the molecules for this penetration to occur is $6.0 \AA$, because the intermediates, in most cases, vary from 4.7 to $5.6 \AA$ [35]. The color formation is based on a series of oxidation and coupling reactions, divided into three main stages:

(a) Quinonamines formation: is the oxidation of low reactivity bases with hydrogen peroxide under alkaline conditions with the formation of monamines from para and ortho-aminophenols, and diamines from $p$-phenylenediamine and $o$-phenylenediamine. The PPD is especially oxidized in a reactive intermediate, the quinoamine that, in the presence of the reaction modifier, will generate a colorful polymer [33].

(b) Diphenylamines formation: cations of quinones formed in the first stage receive an addition of couplers to form a substituted $p$-phenylenediamine.

Nucleophilic compounds including meta couplers and para non-oxidized bases act as couplers because they react with the nitrogen atom of amine-quinones. As an example, there is the formation of diphenylamines from the reaction of $p$-phenylenediamine with $m$-phenylenediamine [24]. Thus, a full range of substituted diphenylamines from other para bases amine-quinones and other non-oxidative bases may be formed. 
(c) Color formation: Diphenylamines formed can be considered as new oxidation bases, in which one of the benzene rings are tri substituted (1,2,4 or 1,2,5 positions) by electron donor groups. Because of this, they have the same potential, possibility of oxidation, and coupling capacitance that the original para bases from which they are derived [10].

The intermediate compound formed in these $p$-phenylenediamine trimers is Bandrowski's base which is considered a primary intermediate in the color formation. The process occurs at a slow rate in the presence of hydrogen peroxide (30 to $45 \mathrm{~min}$ ), which is interesting for the penetration of these intermediates in the cortex. The molecules are initially small in size and are then transformed into Bandrowski's base with greater size than those that do not have a satisfactory penetration [35].

Various parameters may affect the color formation in the hair dyeing process, such as $\mathrm{pH}$, pause time, hair keratin, and purity of the dye molecule, amongst others.

The variation of the $\mathrm{pH}$ value directly influences the reaction rate because a more alkaline $\mathrm{pH}$ favors the reaction and facilitates the cuticle opening, allowing the penetration of molecules into the cortex [28].

The pause time is essential for a complete reaction between the bases and reaction modifiers to occur. According to the manufacturer's guidelines, the product must be in contact with the hair from 30 to $45 \mathrm{~min}$ after application because it is then possible to ensure color reproduction and durability to washing. The removal of the product in a shorter time can stop the reaction before it is complete, creating a variance in the final color [24].

\section{Conclusions}

Among the various options of hair dyes, it is interesting to know the application features and their affinity for the hair fibers in order to select the best option for each hair type and to provide a satisfactory effect, as a good covering power of gray/white hair, good color resistance to shampoo washes, and high durability of color. The challenge is to find options that provide security in the application and allow these benefits to occur without generating very aggressive damage to the hair strands.

\section{Acknowledgments}

We thank Fundação de Amparo à Pesquisa do Estado de São Paulo (FAPESP) for financial support (FAPESP Process: 2013/16070-8).

\section{Author Contributions}

Simone Aparecida da França and Michelli Ferrera Dario wrote the paper; Victoria Brigatto Esteves drew all images; André Rolim Baby and Maria Valéria Robles Velasco reviewed the paper.

\section{Conflicts of Interest}

The authors declare no conflict of interest. 


\section{References}

1. Harrison, S.; Sinclair, R. Hair coloring, permanent styling and hair structure. J. Cosmet. Dermatol. 2004, 2, 180-185.

2. Ahn, H.J.; Lee, W.S. An ultrastuctural study of hair fiber damage and restoration following treatment with permanent hair dye. Int. J. Dermatol. 2002, 2, 88-92.

3. Sherrow, V. Encyclopedia of Hair: A Cultural History; Greenwood Press: Westport, CT, USA, 2006.

4. ABIHPEC-Associação Brasileira das Indústrias de Higiene, Perfumaria e Cosméticos. Anuário 2012. Available online: http://www.abihpec.org.br (accessed on 20 December 2014). (In Portuguese)

5. Feughelman, M. Morphology and properties of hair. In Hair and Hair Care; Johnson, D.H., Ed.; Marcel Dekker: New York, NY, USA, 1977.

6. Robbins, C.R.; Crawford, R.J. Cuticule damage and the tensile properties of human hair. J. Soc. Cosmet. Chem. 1991, 42, 59-60.

7. Morel, O.J.X.; Christie, R.M. Current trends in the chemistry of permanent hair dyeing. Chem. Rev. 2011, 111, 2537-2561.

8. Bouillon, C.; Wilkinson, J.D. The Science of Hair Care; Taylor \& Francis: Boca Raton, FL, USA, 2005.

9. Rogers, G.E. Hair follicle differentiation and regulation. Int. J. Dev. Biol. 2004, 48, 163-170.

10. Wilkinson, J.B.; Moore, R.J. Cosmetologia de Harry; Ediciones Diaz de Santos: Madrid, Spain, 1990. (In Spanish)

11. Wagner, R.C.C.; Kiyohara, P.K.; Silveira, M.; Joekes, I. Electron microscopic observations of humam hair medulla. J. Microsc. 2007, 226, 54-63.

12. Sadaie, M.; Nishikawa, N.; Ohnishi, S.; Tamada, K.; Yase, K.; Hara, M. Studies of human hair by friction force microscopy with the hair-model-probe. Colloid Surf. B 2006, 51, 120-129.

13. Draelos, Z.D. Essentials of hair care often neglected: Hair cleansing. Int. J. Trichology 2010, 2, 24-29.

14. Smith, J.R.; Swift, J.A. Lamellar subcomponents of the cuticular cell membrane complex of mammalian keratin fibres show friction and hardness contrast by AFM. J. Microsc. 2002, 206, 182-193.

15. Halal, J. Hair Structure and Chemistry Simplified, 5th ed.; Milady Publishing Company: New York, NY, USA, 2009; p. 304.

16. Chandrashekara, M.N.; Ranganathaiah, C. Chemical and photochemical degradation of human hair: A free-volume microprobe study. J. Photochem. Photobiol. B 2010, 101, 286-294.

17. Robbins, C.R. Chemical and Physical Behavior of Human Hair, 5th ed.; Springer: New York, NY, USA, 2012; p. 724.

18. Briki, F.; Busson, B.; Kreplak, L.; Dumas, P.; Doucet, J. Exploring a biological tissue from atomic to macroscopic scale using synchrotron radiation: Example of hair. Cell. Mol. Biol. 2000, 46, 1005-1016.

19. Boga, C.; Delpivo, C.; Ballarin, B.; Morigi, M.; Galli, S.; Micheletti, G.; Tozzi, S. Investigation on the dyeing power of some organic natural compounds for a green approach to hair dyeing. Dyes Pigment. 2013, 97, 9-18. 
20. Wolfram, L.J. Hair cosmetics. In Handbook of Cosmetic Science and Technology; Barel, A.O., Paye, M., Maibach, H.I., Eds.; Marcel Dekker: New York, NY, USA, 2001.

21. Draelos, Z.K. Hair cosmetics. Dermatol. Clin. 1991, 9, 19-27.

22. Ghosh, P.; Sinha, A.K. Hair colors: Classification, chemistry and a review of chromatographic and electrophoretic methods for analysis. Anal. Lett. 2008, 41, 2291-2321.

23. Wenninger, J.A.; Canterbery, R.C.; Mcewen, G.N.J. International Cosmetic Ingredient Dictionary and Handbook, 8th ed.; Cosmetic, Toiletry and Fragrance Association: Washington, DC, USA, 2000.

24. Les Colorants Wackherr (LCW). Apresentação Técnica Sobre Tinturas Capilares; LCW: São Paulo, Brazil, 2008. (In Portuguese)

25. Brown, K.C. Hair coloring. In Hair and Hair Care; Johnson, D.H., Ed.; Marcel Dekker: New York, NY, USA, 1997.

26. Wong, M.Y.M. The kinetics of dye rinse from bleached hair. J. Soc. Cosmet. Chem. 1972, 23, $165-170$.

27. Ballarin, B.; Galli, S.; Morigi, M. Study of dyeing properties of semipermanent dyestuffs for hair. Int. J. Cosmet. Sci. 2007, 29, 49-57.

28. Morel, O.; Christie, R.M.; Greaves, A.; Morgan, K.M. Enhanced model for the diffusivity of a dye molecule into human hair fibre based on molecular modelling techniques. Color. Technol. 2008, 124, 301-309.

29. Oliveira, R.A.G.; Zanoni, T.B.; Bessegato, G.G.; Oliveira, D.P.; Umbuzeiro, G.A.; Zanoni, M.V.B. A química e toxicidade dos corantes de cabelo. Quim. Nova 2014, 37, 1037-1046. (In Portuguese)

30. Bolduc, C.; Shapiro, J. Hair care products: Waving, straightening, conditioning and coloring. Clin. Dermatol. 2001, 19, 431-436.

31. Kojima, T.; Yamada, H.; Yamamoto, T.; Matsushita, Y.; Fukushima, K. Dyeing regions of oxidative hair dyes in human hair investigated by nanoscale secondary ion mass spectrometry. Colloid Surf. B 2013, 106, 140-144.

32. Hudari, F.F.; Almeida, L.C.; Silva, B.F.; Zanoni, M.V.B. Voltammetric sensor for simultaneous determination of $p$-phenylenediamine and resorcinol in permanent hair dyeing and tap water by composite carbon nanotubes/chitosan modified electrode. Microchem. J. 2014, 116, 261-268.

33. Altman, M.B.S.; Rieger, M.M. The function of Bandrowski's base in hair dyeing. J. Soc. Cosmet. Chem. 1967, 19, 141-148.

34. Tucker, H.H. Hair coloring with oxidation dye intermediate. J. Soc. Cosmet. Chem. 1967, 18, 609-628.

35. Wilmsmann, H. Beziehungen zwischen der Molekfilgrösse aromafischer verbindungen und ihrem Penetrations-vermögen für das menschliche Haar. J. Cosmet. Sci. 1961, 12, 490-500. (In German)

(C) 2015 by the authors; licensee MDPI, Basel, Switzerland. This article is an open access article distributed under the terms and conditions of the Creative Commons Attribution license (http://creativecommons.org/licenses/by/4.0/). 